\title{
La formación profesional en la Unión Europea. Nuevas claves para su interpretación.
}

\author{
Ignasi Brunet Icart \\ Universitat Rovira i Virgili \\ ignasi.brunet@urv.cat \\ David Moral Martín \\ Universidad Rovira i Virgili \\ josedavid.moral@urv.cat
}

Resumen: Este artículo analiza el sistema de Formación Profesional (FP) de tres países concretos, representantes de cada uno de los denominados modelos clásicos, junto a una breve incursión en el modelo español. Además, valora el actual momento del proceso de convergencia. Para ello apuesta por una aproximación diferente a las utilizadas en la actualidad, mediante la incoporacion de diferentes elementos que normalmente no suelen ser considerados de cara a realizar este tipo de aproximación descriptiva. Es por ello por lo que, junto a la instrucción, introducimos su recorrido bistórico, junto a aspectos referidos al mercado de trabajo y la estructura administrativa nacional. Los inicios de esta transferencia de conocimientos han sido ubicados en la Baja Edad Media, junto a las corporaciones profesionales. En la Edad Moderna se originó la primera escuela primaria que adoptó una formación más genérica, si bien exclusiva. A partir de la II Revolución industrial un nuevo sistema de educación profesional bizo más eficiente la mano de obra, naciendo los sistemas «clásicos» de FP (liberal, burocrático $y$ dual). Finalmente, entre las últimas décadas del siglo $\mathrm{xx} y$ las primeras del XXI ba emergido un movimiento de unificación en materia de formación profesional dentro de la Unión Europea. Otros aspectos necesarios para nuestra aproximarnos a elementos que son considerados ajenos, como las relaciones laborales de los respectivos mercados de trabajo, asi como también las formas de ejercer la administración politica.

Palabras clave: formación profesional; corporaciones profesionales; mercados de trabajo; sistema educativo. 
Vocational Education and Training in the European Union. New keys to its interpretation

\begin{abstract}
This article analyzes the Vocational Training (VT) system of three specific countries, representing each of the so - called classic models, as well as a brief foray into the Spanish model. It also assesses the current momentum of the convergence process. In order to do so, it relies on a different approach to those used today, through the incorporation of different elements that normally are not usually considered in the face of this type of descriptive approach. That is why, along with the instruction, we introduce your historical journey, along with aspects related to the labor market and the national administrative structure. The beginnings of this transfer of knowledge have been placed in the Late Middle Ages, along with professional corporations. In the Modern Age originated the first primary school that adopted a more generic, if exclusive formation. From the II Industrial Revolution a new system of professional education made the labor force more efficient, creating the "classic» systems of FP (liberal, bureaucratic and dual). Finally, between the last decades of the twentieth century and the first of the XXI, there has emerged a movement of unification in the field of vocational training within the European Union. Other aspects necessary for our approach to elements that are considered alien, such as the labor relations of the respective labor markets, as well as ways of exercising political administration.
\end{abstract}

Keywords: vocational training; professional corporations; labor markets; educational system. 


\section{Introducción}

La formación profesional (FP) europea está íntimamente relacionada a determinados aspectos no siempre tratados, como la vinculación que guarda con diferentes periodos históricos. Elemento poco frecuente a la hora de su estudio, peor del que no se puede decir que no haya estado presente. Heikkinen (2004:34) ha señalado que «la conexión entre educación, historia y programas de orden político o cultural resultan menos transparentes a escala internacional que a escala nacional», lo que nos sitúa ante una nueva oportunidad de crecimiento en su análisis, escribir su historia internacional. Sirvan estos apuntes para contribuir a ello.

El modelo de formación basado en el conocimiento exclusivo del oficio tuvo su comienzo junto a las primeras formas de transmisión de conocimientos profesionales, el cual lo hemos ubicado entre la Baja Edad Media y la Edad Moderna. Transferencia hegemonizada por una institución profesional muy concreta que estuvo presente en toda la europa católica, y a la que hemos denominado corporación profesional frente a la más conocida de gremios (Moral Martín,2016). Etapa que aparece al principio de un proceso, cuyo final tuvo que ver con la aparición del capitalismo de base industrial, y que propició la creación de los actuales modelos de formación profesional, cuya consolidación se produjo a partir de mediados del siglo xx. Nuevo sistema de educación profesional necesario para hacer más eficiente la mano de obra, adecuándola a un nuevo tipo de explotación fabril. Ello tuvo lugar durante la II Revolución Industrial (1870-1930), junto a la aparición de los tres modelos clásicos: liberal, burocrático y dual. Modelos adecuados a diferentes estructuras políticas y económicas, si bien de ámbito nacional. No fue hasta mediados del siglo xx, durante la Guerra Fría, cuando los citados modelos tuvieron un doble impacto en la sociedad, aumentando la competitividad de las respectivas economías, debido al incremento de cualificación de la población, asumiendo una nueva función social, al constituirse en una vía de promoción social ascendete de la clase trabajadora.

Finalmente, a finales del siglo xx y comienzos del xxi se ha planteado un nuevo escenario, el de la búsqueda de un modelo común de FP que concierna a toda la Unión Europea (UE). Apuesta vinculada a las recientes estrategias europeas en torno a la formación profesionalizadora. En concreto, ésta se basa en considerar a los centros de FP como agentes constituyentes de las infraestructuras de conocimiento de las que se ha de dotar la UE. Su importancia estriba en que una FP de alta calidad, se convierte en un elemento esencial a la hora de tratar convertir a la UE en la economía del conocimiento más dinámica del mundo. Estudios recientes han confirmado esta estrategia, al resaltar que las competencias de: representación, participación, colaboración, negociación y resolución de conflictos en los 
diferentes ámbitos de las organizaciones, resultan fundamentales para la mejora de la competitividad regional y nacional de la UE en el actual capitalismo global.

Es por todo ello por lo que el objetivo del artículo es describir estos cambios, así como abrir el debate acerca del papel que ha de tener la FP en el actual modelo económico. Para ello, el primer apartado introduce una breve incursión histórica sobre los inicios de los sistemas de educación profesionalizadora. El segundo, identifica y describe la configuración de los mercados de trabajo y de las administraciones centrales nacionales, para ayudar a la explicación del sentido de cada uno de los citados modelos. El tercero, detalla a cada uno de los tres modelos de FP clásicos. El cuarto, y último, apartado se acerca al tratamiento de la FP a nivel comunitario. Finalmente, concluimos con un conjunto de conclusiones extraídas del propio texto.

\section{Los orígenes de los sistemas de aprendizaje en el trabajo}

El comienzo de la Edad Media vino acompañada del renacimiento de vida urbana. Ciudad que ha sido definida por Weber (1987:5) como un lugar de mercado: «la ciudad es, pues, en el sentido que aquí le otorgamos a esa palabra, un asentamiento comercial». Ámbito de intercambio de mercancías que estuvo vinculada a la aparición de una oferta y de una demanda, y en la que la presencia cada vez mayor de consumidores estuvo satisfecha por nuevos agentes económicos: «fueron más numerosos los artesanos y los comerciantes» (Pirenne, 2011:90).

La institución encargada de organizar la producción fueron las corporaciones profesionales (Moral Martín,2016), que a finales del siglo xviri (bajo el inicio del liberalismo) pasaron a ser denominadas gremios (Molas,1970). Durante su vigencia, estas instituciones se encargaron de producir todo lo necesario para el mantenimiento de la ciudad. Una producción de bienes y prestación de servicios que fue posible gracias a la existencia de un numeroso numero de oficios legitimado para cualquier producción o servicio, motivo por el que la transmisión de conocimientos, del savoir faire de éstos, fue llevada a cabo en su interior. Es por ello por lo que todos los oficios formaron a sus miembros en las actividades y conocimientos necesarios para su desarrollo.

A finales de la Baja Edad Media, tuvo lugar un gran auge de los oficios corporativos, entre otras cuestiones por la ampliación del ámbito urbano. Ello provocó una estrategia vinculada al reparto del mercado y la consecuente aparición de rivalidades entre oficios. Época que fue conocida como la «revolución del oficio» (Pirenne, 2011), ya que alumbró un proceso de paricipación de la voz profesional 
en los órganos de decisión política del poder temporal. Situación que se prolongó durante la Edad Moderna. Como resultado de este contexto de competencia se produjo una mayor rigidez en la estructura jerárquica interna corporativa, motivo por el que nació la clásica trinitaria división entre maestro, oficial y aprendiz. Para ello se utilizó la figura del examen que conocida desde el siglo xiII, «se hará obligatoria en el siglo xiv, da directamente acceso al maestrazgo» (Martin Saint-Léon, 1947:221). En España Collantes de Terán (1992:122) ha señalado la coincidencia de fechas: «el siglo XIV vio también aparecer una institución que se convertiría en una de las bases del régimen corporativo: la obra maestra». Sennet (2009:78) ha descrito un caso ideal de éste, diferenciándolo en dos fases: «la presentación de la obra maestra (chef d'oeuvre) que realizaba el aprendiz al cabo de sus siete años de aprendizaje (...). Si aprobaba, ya oficial, trabajaría durante otros cinco o diez años hasta que pudiera demostrar, con una obra maestra superior (chef d'oeuvre élevé), que merecía ocupar el lugar del maestro». Proceso que duró hasta prácticamente el final del Antiguo Régimen entre los artesanos, tal y como lo ha descrito Villalonga (2010:11) en Examen d'un mestre sabater. Sainete costumbrista en el que se narra el «ambient dels gremis barcelonins del segle xvirI tot recreant l'examen d'un aspirant a estre de l'ofici».

Acceso a maestro no quiere decir impartir magisterio. No debemos confundir el origen de la actual FP, en la que se establece una formación integral del alumno bajo una clara orientación profesional, a los conocimientos impartidos en estas corporaciones profesionales, ya que éstas sólo bucaban la reproducción del oficio, es decir, la transmisión del conocimiento necesario para su ejecución. Ejemplo de ello es el clásico ejemplo recogido por Uña de Sarthou (1900:202) para los sastres burgaleses (1500), en los que se enseñaba a cortar «la ropa al pospelo o al través, ni [que tampoco] tengan borra los jubones».

En parte esta forma de organizar el conocimiento se ha de vincular a una ubicación social dada por el estamento al que perteneciera, por lo que la posibilidad de movilidad social fue muy reducida y poco atribuible a sus competencias profesionales, esto explicaría el que si bien existieron artesanos que se enriquecieron, fueron los menos, el modelo de «desigualdad limitada» (Nieto y Zofio ${ }^{1}$,2015). Además, hay que tener en cuenta que la citada transmisión de conocimientos estuvo situada en el centro de una compleja y amplia trama de relaciones familiares y personales entre familias, individuos y artesanos, por lo que no influyó la «vocación» del futuro maestro, ahora candidato a aprendiz. Motivo por el que también se enseñaba todo un conjunto de normas morales y de conductas éticas para su incorporación a la comunidad vinculada a un oficio concreto. Esto explica el

1 Nieto Sánchez, José Antolín y Zofío Llorente, Juan Carlos (2015). «Los gremios de Madrid durante la Edad Moderna: una revisión». Areas: Revista internacional de ciencias sociales, n 34, pp. 47-61. 
porqué existieron corporaciones profesionales que no prestaron atención a cuestiones para nosotros básicas, como la enseñanza de la lectura y de la escritura, sobre todo en aquellos oficios en los que no fuere menester tales habilidades, nos referimos a descargadores, los trajineros y los manobras de construcción (Moral Martín, 2016).

Para identificar una educación dotada de un carácter integral, pero con escaso contendio profesional, debemos esperar hasta las primeras escuelas modernas. Boli et alii (1977) ha señalado que su creación tuvo lugar a lo largo del siglo XvI. Su aparición debe vincularse a la expansión del modelo europeo de sociedad nacional, el cual fue construido a partir de la coincidencia de tres procesos diferentes (políticos, sociales y económicos) en un momento de profundas transformaciones: la reforma y contrarreforma religiosa; la expansión de la economía mercantil, y la institucionalización de un sistema político internacional de Estados-nación, superador de los viejos Estados monárquicos sobrepasado por la idea de la nación soberana. Este nuevo marco político recibe su definitiva confirmación a través de la paz de Westfalia, en 1648 (Brunet et alii, 2016). Con anterioridad las experiencias estatales estaban mucho más aisladas: pequeños núcleos de ciudadesEstados rodeados por formas organizativas más primitivas (preestatales). O bien Imperios que, dada su superioridad, van absorbiendo comunidades pre-estatales pero, en función de dicho proceso, se convierten en la única forma de perfil estatal existente en vastos territorios, de manera que, paradójicamente, su misma presencia impide la proliferación de Estados (en plural) (Baqués, 2011).

El Estado nacional y concretamente el Estado liberal de derecho arrasó al Estado absolutista de legitimación divina, apoyándose en el poder judicial (que debía juzgar la observación de las conductas y los sujetos a las normas que la sociedad se había otorgado para su convivencia) y el poder de la institución escolar (que debía inculcar las normas de conducta que la sociedad nacional se otorgaba para su convivencia). Concretamente, en su edad de madurez, el Estado nacional va a tener como plataforma, a partir de finales del siglo xviII, al modelo de enseñanza nacional, que comenzó con lo que hoy se llama la Revolución Industrial y que produjo cambios profundos en la sociedad debido al surgimiento de las fábricas industriales (mayoritariamente textiles) en Inglaterra. A finales del siglo xVIII, y bajo las revoluciones americana y francesa, se dio paso a la ciudadanía y al Estado moderno nacional

Según han señalado Wollschläger y Reuter-Kumpmann (2004), la Revolución Industrial provocó una reestructuración radical del sistema de «reabastecimiento de recursos humanos» en todos los países europeos, junto a la emergencia de las clases sociales como nuevo modelo de estratificación social que acabará sus- 
tituyendo al estamental, iniciadno un viaje hacia el contrato (Laski, 2014). Este contexto pareec justificar el porqué la revolución industrial necesitó que el poder político se hiciese cargo de la alfabetización de sus ciudadanos; algo no imposible, pero prescindible en sociedades agrarias, autárquicas y artesanales. Hecho lógico si lo vinculamos a las nuevas formas de extracción de la plusvalía fabriles, lo que necesitó de formas de explotación más eficiente de los medios de producción, incluyendo a la encargada de ponerla en funcionamiento, la mano de obra. Alfabetización que tuvo una función adaptada, la de educar en el respeto al nuevo orden político que surgió con la modernidad. Es por ello por lo descansó sobre tres pilares: la consolidación del Estado-nación, los sistemas educativos modernos fueron creados para su consecución; la emergencia de la burguesía como clase dominante, reclamadora del control político del Estado para subordinarlo a sus intereses liberales; y el reconocimiento de los derechos de ciudadanía, que se irán ampliando, aunque muy lentamente, a toda la población (Brunet et alii, 2016).

Lo anterior nos muestra una situación que permite entender el interés demostrado por los Estados nacionales por utilizar el poder de la institución escolar, e iniciar así un proceso de control interior de sus límites. Hecho reflejado en la puesta en marcha de un completo proceso de burocratización (dotación de una estructura administrativa) con la que se persiguió una homogeneización social entre los súbditos del reino (costumbres, hablas y prácticas). Aparece así el contexto en el que se ha de incluir la creación del sistema de educación nacional, y la consecuente creación de escuelas a lo largo y ancho de todo el territorio nacional, con el exclusivo propósito de adiestrar y disciplinar al alumnado en un nuevo modelo de ciudadanía política y laboral, todo ello acompañado de una acción metódica y subordinada. Estandarización llevada a cabo por un nuevo colectivo profesional, los profesores. Su participación en la construcción del Estado-nación se basó en la instauración de un cierto modelo de enseñanza basado en la creación de: un sistema de oposición pública, un currículo nacional base (que todos los alumnos han de compartir) y de exámenes que permitían jerarquizar a los ciudadanos en función de sus méritos (Brunet et alii, 2016).

Acher (1979) ha resaltado el hecho de que si bien la génesis es similar, no todos los sistemas educativos nacionales siguieron el mismo modelo. Sistemas que no obstante compartieron un patrón similar, una estrategia de jerarquización caracterizado por «mitos meritocráticos» como han señalado Boli y Ramírez (1999). Conjunto de procesos de puesta en práctica de determinados valores y creencias ideológicas: el individuo, coincidiendo con el inicio del liberalismo; la nación, o el conjunto de éstos; el Estado como guardián de la nación; el progreso, tanto nacional como individual; y la socialización y continuidad del ciclo de vida. 
Mitología que sostuvo, legitimó y reforzó un modelo europeo de sociedad nacional, a la vez que justificó sus desigualdades (sociales, políticas y económicas). No resulta extraño, pues, el uso de la institución escolar como uno de los principales instrumentos utilizados, aspecto que ha sido señalado por Brunet et alii (2016). Tampoco su esfuerzo en olvidar que la división técnica del trabajo era resultante de las divisiones sociales, es decir, del particular sistema de relaciones de fuerza entre los grupos sociales en un momento determinado. De este modo, se despertó y fomento la creencia en la legitimidad de un particular sistema de relaciones de fuerza o de dominación (Weber, 2002).

La formación de los sistemas educativos nacionales durante los siglos XVIII y XIX, vino acompañada de la aparición de la FP, como ha señaldo Archer (1979). Concretamente, Greinert ${ }^{2}$ (1990) ha ubicado sus modelos clásicos a mediados del siglo xix, junto a la II Revolución Industrial. Muy relevante es constatar que en el origen de estos estudios genéricos (no estrictamente profesionales), se pudo identificar la existencia de un conflicto social entre los poseedores de las instituciones de enseñanza, (los órdenes religiosos y, en menor medida, la burocracia y los miembros del aparato estatal) y los nuevos grupos sociales que aumentaron cuantiva y cualitativamente, y a los que podemos identificar como los representantes del modelo europeo de sociedad nacional, la burguesía industrial o comercial. Los enfrentamientos que hubo entre ellos explican al menos parcialmente, el surgimiento de diferentes sistemas educativos nacionales, si bien sobre la base de un modelo común de sistema educativo: estatal y de masas. Un patrón que reforzaba institucionalmente las condiciones sociales y simbólicas, naturalizando las diferencias entre posiciones sociales al presentarlas como diferencias de: mérito, talento, esfuerzo.

Archer (1979) ha estudiadiado como si de tipos ideales weberianos se tratase este aspecto en los casos de Francia e Inglaterra. El primero, denominado de estrategia de restricción. El reflejo del enfrentamiento existente entre colectivos sociales se pudo observar con la creación de un sistema educativo estatal en el siglo XIx, el cual estuvo vinculado a los recursos políticos disponibles de diferentes grupos sociales que lucharon por hacerse con el control de la enseñanza. Motivo por el que determinados colectivos laicos buscaron arrebatar el control de la enseñanza a las órdenes religiosas. Para ello trataron de ofrecer una alternativa a educativa que restringió las llevadas a cabo por los tradicionales propietarios de los medios de enseñanza, posibilitando la construcción de un sistema educativo estatal, de marcado carácter público. El segundo, la estrategia de substitución. Los

2 Greinert, Wolfrang (1990). «Fortbildungsschule im deutschen Kaiserreich. Die wichtigen Jahren von 1895 bis 1914». In Lisop, I.; Greinert, W.-F.; Stratmann, K. (eds.). Gründerjahre der Berufsschule. Berlin und Bonn: BIBB. 
nuevos grupos sociales dispusieron de amplios recursos, tanto políticos, como económicos y sociales. Ello les posibilitó ofrecer un sistema educativo paralelo cuasi completo, caracterizado por su apuesta alternativa y su oposición al sistema religioso, lo que sin duda facilitó que fuese introducido sin necesidad de restringir la actividad privada. El resultado de este proceso fue la aparición de dos redes diferentes de escolarización; ambas bajo control estatal. Como resultado de estas estrategias surgieron dos tipos de sistemas educativos estatales, uno centralizado y controlado por el Estado (el modelo de Francia), el otro descentralizado en varios niveles y con una autonomía relativa de las partes que lo integran, pese a que el Estado ejerce un papel notorio (es el modelo inglés, posteriormente británico).

Una vez constituidos los sistemas educativos estatales, Viñao (1982) ha destacado el nacimiento de fuerzas ideológicas y organizaciones, que contribuyeron a cierta dirección dual en la educación secundaria, con todas sus limitaciones y contradicciones. Modelo que recogió la herencia de siglos anteriores, si bien adaptándolas a la búsqueda de identidad social por parte de una nueva clase social nacida al albur del proceso industrializador. Desde un principio requirió la existencia de una educación ambivalente, que fluctuase fundamentalmente entre dos tipos o concepciones de educación secundaria: la humanística y la técnicoprofesional. La introducción entre la citada clase de estudios secundarios con un sentido de utilidad económica e industrial tuvo grandes dificultades de aplicación, ya que un nuevo tipo de enseñanza más utilitaria y profesional no tenía posibilidad alguna de extenderse $-y$ ser deseada - si no conducía a posiciones sociales vinculadas a un mayor prestigio y, por lo tanto, la posibilidad de acceder a una mayor remuneración (Merino, 2010, 2013); cuestión que requirió de profundas transformaciones socioeconómicas previas.

El caso concreto de España refleja perfectamente esta situación. Hasta bien entrado el siglo xx, la enseñanza secundaria humanística quedó disponible tan sólo para una reducida a minoría muy seleccionada socialmente, orientada a continuar sus estudios en la universidad. Frente a ellos, las autoridades patrocinaron ciertas formaciones que sobre la base humanística incorporaban oficios tradicionales. Ejemplo de ello fue la creación por Felipe V, en 1744, de la Academia de Bellas Artes españolas, institución en la que se enseñó «diseño, pintura, escultura y arquitectura, a ejemplo de las que se celebran en Roma, París, Florencia y Flandes, y lo que puede ser conveniente a su real servicio, al lustre de esta insigne villa de Madrid y honra de la nación española ${ }^{3}{ }_{+}$Junto a esta se han de resaltar las iniciativas llevadas a cabo por las corporaciones liberales que se alejaron de los gremios (Juntas y Sociedades de Amigos). En concreto, la Junta de Comercio

3 Texto disponible en: <http://www.realacademiabellasartessanfernando.com>. Visitado el 12 de enero del 2016. 
de Barcelona nació en 1758, bajo el reinado de Fernando VI. Entre sus miembros hubo «un gran pocentaje de comerciantes procedentes de los estamentos superiores de los gremios, así como también algún noble, mercader y hacendado rural, con la particularidad de que todos ellos se dedicaban a actividades mercantiles» (Monés, 1985:243-2444 ). Ésta vehiculó el interés de amplios sectores de la burguesía local preocupados por sus negocios y por adecuar la formación de la mano de obra. Para ello constituyeron ciertas escuelas profesionales, entre las que destacaron la de Náutica y la de Nobles Artes. No debemos olvidar que sus motivaciones que oscilaron entre la filantropía y la necesidad de disponer de una elite de operarios cualificados. A partir de la entrada de los gobiernos liberales, y recogiendo la herencia de escuelas específicas (náutica, bellas artes, etc.), se crearon las escuelas técnicas superiores, si bien sin conexión alguna con una formación profesional primaria o post-primaria. En paralelo, se erigió otro tipo de formación la orientada hacia el trabajo manual, y muy volcada en la asignación de una serie de cualificaciones profesionales, y que tuvo mucho que ver con nuestra actual concepción de la FP. Enseñanza que se la ha de enmarcar en el proceso con el que se intentó acabar con la imagen mecánica y vil de este tipo de trabajos; aspecto confirmado por la aprobación de la Real Cédula de S.M Carlos III, el 18 de marzo de $1783^{5}$ (Díez,19906). Desde sus comienzos este tipo de educación estuvo limitada a la educación primaria, cuya función se orientó a la enseñanza de un tipo de valores ideológicos-morales, de tintes economicistas y fabriles: puntualidad, trabajo bien hecho, disciplina y frugalidad, entre otros comportamientos. Aquí debemos destacar el esfuerzo realizado por los propios obreros de cara a asegurarse una formación, más técnica que humanística, tal y como se demuestra con la creación de numerosos Liceos y centros de estudio.

Otra etapa expansiva del modelo europeo de sociedad nacional a nivel mundial, tuvo lugar a lo largo del siglo xx (a través de la colonización, entre otros motivos). Vino acompañada de un nuevo intento por institucionalizar un esquema universal, añadiendo el principio de igualdad de oportunidades educativas sobre la herencia del principio regulador del mérito. Por ello, las instituciones escolares nacionales adoptaron una nueva función niveladora, en la que que todo

4 Monés i Pujol-Busquets, Jordi (1985). «Enseñanza técnica y profesional y desarrollo socio-económico: el caso de la Junta de Comercio de Barcelona (1769-1851)». Historia de la educación: Revista interuniversitaria, no 4, pp. 241-272.

5 «Por la qual se declara, que no solo el Oficio de Curtidor, sino también los demás Artes y Oficios de Herrero, Sastre, Zapatero, Carpintero y otros á este modo, son honestos y honrados; y que el uso de ellos no envilece la familia, ni la persona del que los exerce, ni la inhabilita para obtener los empleos municipales de la República en que estén avecindados los Artesanos ó Menestrales que los exerciten». Texto disponible en la Biblioteca virtual del patrimonio Bibliográfico: <http://bvpb.mcu.es $>$.

6 Díez, Fernando (1990). Viles y mecánicos: trabajo y sociedad en la Valencia preindustrial. Edicions Alfons el Magnànim, Valencia. 
sujeto, cualquiera que fuese su origen social, hubo de disponer de la oportunidad de alcanzar el nivel más alto de educación que pueda. Situación que ha sido racionalizada en términos contables por Trinidad (2008:155): «los beneficios que la sociedad obtiene de la inversión en educación son netamente superiores a los costes de formación que asume». De ahí que la Unidad Permanente de Lisboa (2005:75) haya resaltado que «el adecuado funcionamiento y la calidad de los sistemas educativos nacionales son clave para la formación del capital humano durante las diferentes etapas educativas», así como para la legitimación de las desigualdades, según ha apostillado Peugny $(2009 ; 2013)$.

Por todo lo expuesto, podemos afirmar que, tras la superación de la etapa formativa vinculada al Antiguo Régimen, y una vez establecidos los rudimentarios cimientos cognitivos, fue cuando se produjo la verdadera formación profesionalizadora, aunque para ello se continuasen conservando las vías tradicionales del aprendizaje directo o las redes comunitarias entre familias y/o corporaciones gremiales. No sería, pues, aventurado vincular la crisis del sistema gremial, cuya prohibición comenzó a finales del siglo xviI (Francia) y culminó a finales del siglo $\mathrm{XIX}^{7}$ (Hungría), con la preocupación por la implantación de un tipo de educación secundaria de orientación humanística y con el incipiente modelo de FP que era llevada a cabo en la institución escolar.

\section{Aspectos socio-laborales a considerar}

a partir de la Revolución Industrial en Europa se produjo una adaptación diferenciada por países a las nuevas necesidades de cualificación. Ello nos ofrece pistas acerca de que el modelo gremial no fue tan homogéneo como a veces se trata de describir, razón por la que necesitamos de buenos estudios sobre la transmisión de conocimientos que se produjo en el mercantilismo, ya que en ella nacieron las denominadas «culturas del trabajo» de cada uno de los países, vinculadas a los primeros procesos proto-fabriles asociado a manufacturas y proto-fábricas $\left(\right.$ Berg $\left.^{8}, 1987\right)$. Esta falta de semejanza limita nuestro análisis, debido a que tan sólo explica parcialmente la existencia de diferentes modelos de FP, relacionándolo con la incorporación nacional al proceso de industrialización. Sin duda, tal como lo ha señalado Greinert ${ }^{9}$ (2004a:17), este aspecto fue esencial: «the most

7 En España el restablecimiento de la supresión de los gremios, fue «acordada por las Cortes de Cádiz, los días 2 y 6 de diciembre de 1836» (Pan-Montojo, 1996:465).

8 Berg, Maxine. (1987). La era de las manufacturas, 1700-1820. Critica, Barcelona.

9 Greinert, Wolf-Dietrich (2004a). «European vocational training systems: the theoretical». En context of historical development Towards a history of vocational education and training (VET) in Europe in a comparative perspective. Proceedings of the first international conference October 2002, Florence, Volume I, pp. 17-27. 
influential factor governing the genesis of vocational training systems for the working masses is undoubtedly the Industrial Revolution or the general industrialisation of the European nations». La relación entre el crecimiento económico y la formación de capital humano ha sido estudiada fundamentalmente desde el punto de vista de la alfabetización, como ha sido señalado por Heredia ${ }^{10}$ (2008). En nuestro caso incoporamos también aspectos estructurales como el propio mercado de trabajo y la administración que albergó los sistemas de tansmisión de conocimientos. Creemos que estas aportaciones nos han de devolver una imagen más aproximada de lo que realmente sucedió.

Centrándonos exclusivamente en la industrialización, parece cierto el hecho de que cada país tuvo una vinculación en función de su propio tempo, lo que explica el porqué existieron países que dirigieron la transformación tecnológica, mientras que otros tan sólo siguieron sus pasos. Incluso, en determinados casos, algunos no llegaron a experimentar una transformación industrial profunda hasta mucho más tarde, los famosos latecomers. Este factor hizo que variase la influencia de los cambios tecnológicos y organizativos, además de hacer muy diferente el desarrollo histórico de los distintos agentes del mercado de trabajo. Todo ello influyó en la configuración y el alcance de los sistemas de FP y, sobre todo, impidió la creación de un único modelo de éste. Todos los países industrializados necesitaron (antes o después) adoptar un tipo concreto de formación profesional, para afrontar retos similares, si bien no idénticos, como ha señalado Nilsson (2007). Entre éstos destacó la creciente demanda de fuerza de trabajo dotada de nuevas cualificaciones exigidas por los nuevos oficios que generó la II Revolución industrial (soldadores, maquinistas y fabricantes de herramientas). En definitiva, esta fue una de las principales razones de la existencia de tres modelos básicos de FP de su consolidación tras la II Guerra Mundial, cuando los sistemas de aprendizaje van a desempeñar un papel clave en la construcción de las sociedades del bienestar europeas, en sí mismas apuestas estratégicas de occidente durante la Guerra Fría (Tessaring, 1999; Tether et alii 2005; Greinert, 1999, 2005; Molinas y García Perea, 2016).

\subsection{Modelos de mercado de trabajo}

Por todo lo visto, hemos entendido que cualquier acercamiento a la FP necesita de un marco analítico amplio, que trate de explicar la lógica subyacente a cada uno de ellos. Para ello empleamos nuevos elementos para describir ciertos componentes institucionales de cada uno de los países representantes de los modelos

10 Heredia Flores, Vïctor Manuel (2008). «Ideología, política y realidad económica en la formación profesional industrial española (1857-1936)». Revista de bistoria industrial, nº 37, pp. 217-220. 
prototípicos de FP apuntado: Gran Bretaña, Francia y Alemania. Concretamente, y en un primer momento, lo hacemos mediante el estudio de la cuestión del mercado laboral. Hoy denominada relaciones laborales.

Toner (2011:59) ha señalado que la revisión de la literatura y experiencias internacionales muestra que la estructura productiva y el tipo de innovación existentes en un país muestran «una fuerte interacción circular y acumulativa». Ello se refleja, a su vez, en las competencias y cualificaciones de la fuerza de trabajo (junto a otros factores institucionales, tales como las regulaciones de los mercados de trabajo), lo que termina reflejando las diferentes especializaciones productivas y comerciales de los territorios. Navarro (2014:6-7), señala que la literatura «distingue tres grandes sistemas de formación de competencias: los modelos de mercado de trabajo flexible, interno y ocupacional, de los que ejemplos arquetípicos serían Reino Unido, del primero; Japón, del segundo; y Alemania, del tercero. Cada uno de estos modelos ejerce distintos efectos en el tipo y nivel de cualificaciones de FP». Nosotros nos centramos en el análisis del ámbito europeo, para ello seguimos la descripción realizada por el propio Greinert ${ }^{11}$ (2004a; 2004b).

Gran Bretaña, primacía de lo económico. Históricamente ha considerado a las relaciones humanas productivas como resultado de su historia liberal y políticamente revolucionaria. Las relaciones profesionales se trataron de un proceso más de un mercado en el que participaron ( 2 ) libremente miembros de la sociedad, es decir, trabajadores y empresarios. Concepción vinculada a la inexistencia de un sistema legislativo protector, lo que ha caracterizado su abstencionismo, entendiendo por éste la no intervención en los procesos del mercado. Así pues, el paradigma fue gobierno de la ley y no de los hombres según. A nivel institucional, presenta un modelo de mercado de trabajo conocido como flexible, cuyas características son: bajos niveles de regulación y de sindicalización, alta rotación laboral, división de la fuerza de trabajo entre un reducido núcleo permanente y una amplia periferia, gran polarización de cualificaciones (gran proporción de graduados universitarios y de trabajadores con mínima o nula cualificación y una pequeña proporción de cualificaciones intermedias), un sistema de FP controlado por los empresarios que proporciona competencias muy específicas, una estructura industrial muy bifurcada con un mayor desarrollo de los sectores de muy alto y bajo nivel tecnológico (pero notable déficit de los de nivel intermedio) y un llamado 'equilibrio de baja cualificación' (la abundancia de trabajadores con baja cualificación y productividad, hace que las empresas se especialicen en productos estandarizados y de baja calidad; la baja demanda de trabajadores de mayor cualificación que de ello se deriva, desincentiva a los trabajadores a que se formen).

11 Greinert, Wolf-Dietrich (2004b). «Los «sistemas» europeos de formación profesional: algunas reflexiones sobre el contexto teórico de su evolución històrica». Revista Europea de Formación Profesional, nº 32, pp. 18-26. 
Francia y su fierte vinculación política. Las relaciones sociales humanas han sido históricamente consideradas como si de un hecho político se tratase. En buena lógica se entiende la reacción de los protagonistas implicados, el Estado y sus poderes ejecutivos, concretamente denominados inspecteurs de travail. Esta insistencia en el aspecto político explica la existencia de un orden público social, vehiculizada por una reglamentación que le confiere al Estado una importante posición de control sobre la vida laboral. El lema paradigmático de esta versión republicana y francesa sería majesté de la loi, como máxima consecución de la Grande Révolution.

El tercer, y último tercer país, es Alemania y su clara apuesta por lo social. Su concepción del mercado de trabajo se basa en considerar a sus relaciones humanas como una especie de comunidad social corporativa, basada en la existencia de una supuesta tradición de responsabilidad recíproca y de respeto al conjunto. Las normas que rigen esta comunidad social, no suelen venir impuestas directamente por la política, tal como hemos observado en el caso británico. Es por ello por lo que «los competidores sociales proponen, elaboran y corrigen por sí mismos dichas normas, hasta cierto punto. [... . Este sistema puede caracterizarse con los paradigmas de 'estado civil constitucional','autonomía privada' y 'ley supervisora'» (Greinert, 2004b:20). Su mercado de trabajo refleja este modelo, al cual lo podemos denominar ocupacional. Se caracteriza por su regulación y una estrecha cooperación entre empleadores y sindicatos, apoyados por el gobierno. Los relativamente altos salarios hacen que se intente evitar la competencia en precio y haya fuerte inversión en capital. La seguridad en el trabajo junto a la alta proporción de trabajadores cualificados (fruto en gran medida de un sistema de formación en alternancia muy bien valorado) facilita la innovación y la adaptabilidad.

Relacionando tanto los sistemas de FP históricos con los modelos de mercado de trabajo, Greinert (2004a 23 ) propone que los tres modelos de FP existentes, deben ser tratados como prototipos generados por las naciones europeas en su búsqueda de nuevos métodos de organizar la FP para todos sus trabajadores, sobre todo tras la industrialización. Modelos en los que se detectan tres ideas o principios «que interactúan específicamente: tradición (principio profesional), racionalismo (principio académico) y liberalismo (principio de mercado)», lo que ha conformado tres principios legitimadores:

1) La orientación al mercado (modelo liberal y de mercado), se vicula al caso británico. Este modelo de legitimación se basa en estimular el esfuerzo individual y la meritocracia, fundamentándose en las enseñanzas y principios del liberalismo económico y en la teoría clásica de la economía nacional. Greinert (2004b: 24) ha ido describriendo estos elementos. En su opinión el «postulado central 
consiste en que las personas son capaces de organizar eficazmente su interacción social, y en particular su vida laboral». El liberalismo económico «rechaza toda intervención estatal en la economía, (...), reclamando a la política estatal que se limite a satisfacer unas pocas exigencias generales de orden básico». Esto provoca que los sistemas de cualificación se limiten a impartir «cualificaciones utilizables en el mercado, esto es, conocimientos prácticos específicos para empresas, capacidades profesionales y actitudes necesarias para puestos concretos de trabajo».

2) La orientación académica francesa (modelo burocrático). Para Greiner ( $2004 b$; 23-24) se basa en «la convicción de que es necesario aplicar la racionalidad académica para implantar un principio didáctico organizativo que sea válido para las cualificaciones profesionales». Idea sin duda «producto inmediato de la Ilustración» por lo que considera que es «la ciencia -sobre todo, las matemáticas y las ciencias naturales- [las que] deben dirigir el mundo, particularmente en el ámbito de la tecnología». De ahí que «la necesaria integración de cualificaciones intelectuales con capacidades prácticas relevantes sigue constituyendo un problema para este modelo».

3) La orientación corporativsa y profesional alemana (modelo dual). Modelo basado «en un caso ideal en la tradición, es decir, por una parte en prácticas profesionales reales aplicadas en Europa desde la Edad Media, y por otra parte en la profesión como forma ensayada y comprobada de categorizar los tipos organizativos de recursos humanos». Esto ayuda a entender el porqué las diferentes profesiones constityen «combinaciones específicas de los elementos trabajo, cualificación e ingresos. Las actividades que implican están determinadas en función de las tradiciones y los acuerdos sociales existentes».

\subsection{Contexto socio-político de los modelos de FP.}

Otra de las diferencias existentes entre modelos de FP, debe ser explicada por los distintos sistemas de Administración Central del Estado. La historia de la Administración Pública en Europa es una parte de la historia de la evolución del Estado contemporáneo, y por ende de su formación humano y profesional. $\mathrm{Al}$ respecto, resaltamos sus dos factores que originales. La centralización de la dominación en el seno de un territorio y con ella la aparición de mayores Estados territoriales. La necesidad de la realización común de tareas permanentes (regulación de las aguas o la organización para la defensa común de territorios comunes). Factores íntimamente vinculados, ya que se retroalimentan: la dominación de un poder central se legitima en la medida que contribuye a la realización de tareas comunes, $y$ viceversa. 
Acudimos a Mayntz (1985), para resaltar particularidades históricas nacionales que revistan importancia para la consolidación de los diferentes modelos de FP europeos en orden de aparición:

Inglaterra, la aparición de una administración estatal de gran extensión tuvo lugar en Inglaterra más bien tarde y fundamentalmente como consecuencia de la necesidad del Estado democrático moderno de asumir prestaciones de regulación y de servicios. A la larga, ello facilitó el desarrollo del sistema de seguridad social británico en la segunda posguerra mundial, basado en el Informe Beverige. No obstante, no se ha establecido todavía en su totalidad el sistema escalonado administrativo continental. Así, entre los órganos administrativos centrales de Londres y los departamentos administrativos locales falta considerablemente la instancia media, característica de la administración francesa y alemana.

Francia, la administración central se trató de instrumento asegurador de pretensiones absolutistas de dominación, por lo que este país ofrece el mejor ejemplo histórico del proceso de centralización del poder. Ello se debe a que, en contraste con Alemania, se alcanzó ya en el siglo xv, tras la Guerra de los Cien Años, una especie de unidad nacional. Ello se reflejó a comienzos del siglo xvi, cuando se estableció un ejército permanente a la vez que la creación de un sistema central de imposición y de recaudación de impuestos mediante funcionarios reales. Paralelamente se creó un sistema de secretarios, especializados por asuntos y regiones, como vértice central de un aparato administrativo en crecimiento. A partir de este sistema de órganos administrativos superiores, se formó durante el primer periodo revolucionario el modelo de la moderna organización ministerial. Napoleón durante su mandato vigorizó la administración central, organizándola según modelos clásicos romano y militar. Para ello estableció una estructura jerárquica con competencias delimitadas y una clara línea de subordinación. Modelo de organización administrativa que se convirtió de referencia para Alemania, así como para otras naciones europeas como Italia y España. A consecuencia de ello, surgieron los ministerios clásicos: Hacienda, Exterior, Interior, Guerra y Justicia, divididos, a su vez, en secciones y negociados.

Alemania, la historia de esta administración se asemeja a las anteriores, pero con la diferencia de que las administraciones estatales no se instalaron en sus divisiones territoriales hasta finales del siglo xix. Por tanto, la fase del Estado Nacional se alcanzó mucho más tarde que en Francia. Para su instauración definitiva cobró especial importancia el proceso de evolución de Prusia, puesto que en este territorio, relativamente grande, se produjo un proceso de centralización que, $y$, además, porque la administración prusiana que adquirió carácter modélico en el Imperio Alemán. a mediados del siglo xviI, se había establecido el fundamento 
del desarrollo de la administración central prusiana: la formación de un ejército regular, el establecimiento de un monopolio impositivo y la administración de los recursos, tanto en el ámbito civil como en el militar. Como en Francia, tuvieron que abolirse las atribuciones estamentales locales, centralizarse bajo el control estatal, y así pudo surgir una administración estatal que descendiera hasta el nivel local. En la época en que se terminó la instauración de una adminstración central escalonada, tuvo lugar una reforma ministerial, en cinco ministerios como en Francia, constituyéndose estos cinco en un Consejo del Estado en 1810, presidido por un Canciller de Estado. Luego se creó un cuerpo de funcionarios, de tipo profesional. La administración central prusiana surgida de este modo se convirtió tras 1871 en el modelo para el Imperio Alemán y permitió en esos años el desarrollo de los seguros sociales implementados por Otto Bismarck. Esta administración caracteriza todavía a la actual administración germana. Sin embargo, en contraste con Francia, no se convirtió Alemania en un Estado unitario en el sentido administrativo, ni siquiera tras la fundación del Imperio en 1871, sino que siguió siendo un Estado federal, aún cuando posteriormente también existieran tendencias centralistas.

\section{Modelos clásicos de FP: liberal, burocrático y dual}

Bajo el sistema de enseñanza nacional fueron desarrollados tres modelos básicos de FP para jóvenes, surgidos durante la primera fase de la Revolución Industrial como respuesta a la pérdida de centralidad «formadora» del antiguo modelo gremial. Para Greinert (1999, 2004a, 2004b, 2005), los modelos: de economía liberal de mercado británico, burocrático y regulado estatalmente de Francia, y el dual-corporativo de Alemania, «arrojan tres modelos estructurales para la formación profesional vigente en Europa» (Greinert, 2004a: 25) y que se replican en otros países del mundo.

El modelo liberal, o de mercado, apareció por primera vez en Gran Bretaña. Ello fue consecuencia de ser el país que inauguró, en el siglo xvir la revolución política que inició el desmontaje del sistema de gremios, ya que abolió la Ley V isabelina sobre el aprendizaje profesional tradicional. Esta decisión fue debido a la nueva situación productiva que trajo la I Revolución Industrial. La maquinaria fabril fue operada por trabajadores especializados, pero sin una formación adecuada, por lo que su explotación continuó la lógica preindustrial de bajo salario como defensa ante la posesión del ocio (Gallego, 1989). Situación que mostró la carencia educativa de éstos y la necesidad de cierta profesionalización. Dos modelos de pensamiento, el liberalismo y el puritanismo, influyeron vivamente en este modelo. Por un lado, el liberalismo basado en la no intervención por parte 
del Estado, reponsabilizó a cada individuo de su propio destino, siempre al albur de la existencia de un libre juego de fuerzas que fomenta el bienestar del país y de sus empresas. Por otro, el puritanismo consideró que la prosperidad es resultado de la capacidad de auto sacrificio y laboriosidad de la ciudadanía, de ahí su condena a la ociosidad y a la tentación del derroche (Revista europea de FP, 2004:9).

Ambas concepciones convergieron en un interesante acuerdo de cara a nuestro propósito, los principales protagonistas del mundo del trabajo y del capital no debían sujetarse a restricciones tradicionales. Ello supuso que el nuevo subsistema educativo fuese impelido a mantener relaciones de libre mercado, es decir negociar en el mercado eltipodeformación que debe impartirse (Revista europea de $\left.F P^{12}, 2004: 10\right)$. En la misma línea, Navarro $(2014: 8)$ opina que la coordinación de la oferta y demanda de habilidades tuvo lugar por el mercado, «el gobierno se ocupa de la provisión de la educación básica necesaria para la producción industrial, pero el modo dominante de formación de habilidades es la formación en la empresa». Por tanto, los contenidos los determinan las empresas en función de sus necesidades y, aunque éstas pueden financiar cursos ocasionalmente, es en general la persona que recibe la formación quien debe financiarla. En este sistema, según Molinas y García Perea (2016), no hay supervisión de la formación por parte del Estado ni exámenes finales acreditados, aunque puede haber certificaciones privadas de competencias adquiridas.

Pedraza (2000:323-333), ha descrito este sistema de FP como controlado por la industria y el mercado, caracterizándolo por su heterogeneidad, diversidad y descentralización. Ello debido a la peculiariedad administrativa (la regionalización) que históricamente ha existido en el sistema educativo británico, más concretamente en el inglés. El autor describe sus tres momentos clave:

- 1986. Creación del sistema nacional de cualificaciones profesionales (NVQ). Representa la formación en o para el trabajo, siendo el marco conceptual cuyo objeto es la creación progresiva de estándares nacionales de cualificación. Se encuentra bajo la autoridad del National Vocational Qualification Council (NVQC). El dispositivo de estandarización de competencias se articuló inicialmente a partir de comisiones profesionales (Industrial Lead Bodies), constituidas desigualmente por representantes profesionales y sindicales, encargados de desarrollar perfiles profesionales bajo la metodología establecida por el NVQC;

+ 1992. Creación del sistema nacional de cualificaciones profesionales generales (GNVQ). Surgió como una vía intermedia entre lo académico

12 Revista Europea de Formación Profesional (2004). «De la divergencia a la convergencia: una historia de la formación profesional en Europa», n 32, pp. 6-17. 
general y lo profesional, por lo que permiten tanto la incorporación al mercado de trabajo como la continuación académica, a través de cursos imaprtidos en escuelas y centros de educación. Fueron implantadas como respuesta a necesidades de los empleadores y están estructuradas en tomo a tres niveles: básico, intermedio y superior, comprendiendo 14 áreas de conocimiento;

- 1997. Creación de la denominada Qualifications and Curriculum Authority (QCA). Significó la fusión institucional de la gestión de titulaciones de carácter profesional y de índole general; el NCVQ y la School Curriculum y Evaluación Escolar (SCAA). Además asesora al Departamento de Educación y Empleo en temas relacionados con el curriculum, las valoraciones de los alumnos y las titulaciones que se ofrecen en centros de enseñanza y de trabajo.

En Francia tuvo lugar la primera aplicación del modelo burocrático de regulación estatal. Éste utilizó un nuevo subsistema educativo, como fue la enseñanza, para reforzar el poder económico y militar de la nación. De ahí se colige, en opinión de DSaunier (2004), que la creación de la FP reglada sirvió para crear una relación política de fuerzas entre el capital y la mano de obra. Navarro (2014: 8 ) ha señalado que los trabajadores estructuralmente desfavorecidos recibieron una cualificación mediante un sector educativo regulado y financiado estatalmente (también incluyó a la FP), con la intención de que pudiesen afrontar las exigencias del capital. Una de las principales diferencias con el modelo anterior es precisamente su regulación pública: «es el gobierno el que controla la oferta y demanda de habilidades. Ello suele ir ligado con frecuencia a un mayor peso de la formación basada en la escuela y con un alto perfil académico». Por tanto, es el Estado el que organiza la FP en colaboración con las escuelas profesionales, que se financian con los fondos que recaudan de las empresas. Esto explica el porqué la formación no está enfocada a adquirir los conocimientos específicos que necesitan las empresas, sino a proporcionar conocimientos generales y técnicos a un alumnado que obtiene un certificado que le permite acceder a cursos superiores.

Modelo que continúa vigente, si bien con ciertas adaptaciones. A comienzos del sigo XXI, «la educación prioritaria de estudiantes y centros escolares desaventajados se basa, en Francia, principalmente en la Red de éxito escolar (Réseau de réussite scolaire, RRS, 2006) y en Escuelas, colegios y liceos para la ambición, la innovación y el éxito (Écoles, collèges et lycées pour l'ambition, l'innovation et la réussite, Éclair, 2011), donde un tercio del total se clasifican como prioridad educativa. La RRS y la Éclair fomentan la continuidad del aprendizaje a lo largo de la educación obligatoria. Las reformas de la FP de secundaria superior (2009) 
trataron de elevar la cualificación de los jóvenes para conseguir una mejor integración de estos en el mercado laboral o en la educación terciaria, y reducir el abandono escolar antes de alcanzar cualificación formal alguna. En el nivel de educación terciaria, la Ley del 22 de julio de 2013 reafirmó la importancia de establecer medidas que promuevan la integración en el mercado laboral. La experiencia de ambientes de aprendizaje en el trabajo (prácticas de aprendices, traslados, etc.) es ahora obligatoria en las cualificaciones en cursos de formación profesional y en los másters» (OCDE, 2015:12).

En Alemania el modelo corporativo dual surgió como una continuación del sistema de aprendizaje corporativo (idealizado en la figura de los gremios), pero contando con la colaboración del Estado. Moriel (2012) ha señalado que el fiel reflejo de esa creeencia fue la reinstauración en 1897 de la formación artesanal tradicional. Para lograr una más adecuada explicación hemos de acudir a dos motivos subayecentes. La fuerte competición internacional incrementaba la necesidad de trabajadores cualificados para puestos industriales y administrativos. Junto a ello. También hemos de considerar el hecho de la existencia de un movimiento obrero cada vez con más fuerza. Esto nos aporta una nueva interpretación de esta estrategia; más allá de la cuestión romántica. Mediante la recuperación de sistemas de aprendizaje tradicionales, el gobierno ocultaba la transmisión de ideologías conservadoras y corporativas en la mentalidad de los jóvenes obreros, por otro lado idóneas para una economía con un alto grado de apertura. Ello explica el porqué durante el siglo xıx, los aprendices asistieron a escuelas de perfeccionamiento en las que «además de una formación estrictamente profesional, enseñaban también a sus alumnos capacidades cívicas». Escuelas que se transformaron, hacia finales del siglo, en profesionales. Ahí radica el sistema dual, estrategia formativa basada en que los alumnos reciben formación en el trabajo y en la escuela (cívica) profesional (Moriel, 2012).

Lo anterior nos permite comprender la actualidad este sistema, y el hecho de que se encuentre fuertemente organizado por las cámaras de comercio (reguladas por el Estado). Además, explica porqué el contenido de la formación se establece multilateralmente. Tal como lo han descrito Molinas y García Perea (2006:148), las empresas «pagan la formación impartida dentro de la empresa, los aprendices reciben un salario por trabajar durante el periodo de formación y las escuelas profesionales están financiadas por el Estado. Las cualificaciones acreditan a escala nacional a los titulados para trabajar en la profesión correspondiente y para acceder a cursos superiores». Como vemos la intervención de instituciones intermedias revitalizadas y tradicionales (el sistema de cámaras) que administran y gestionan la cualificación de los trabajadores en nombre del Estado o de los 
Estados (Länder) regionales, permite al menos compensar algunas de las deficiencias del Estado y del mercado. Ello es posible debido a que la coordinación de la demanda para el suministro de habilidades se lleva a cabo de forma tripartita (Estado, Länder regionales y las asociaciones profesionales). Euler (2013:39) ha identificado como una de las características del sistema dual de la FP, la estrecha interrelación de actores pertenecientes a la economía y al Estado. En concreto «se pone de manifiesto en un entrecruzamiento de principios del corporativismo y el federalismo. Mientras que el Estado y los Länder asumen las tareas de regulación y apoyo, las responsabilidades centrales recaen en las empresas o en gremios estructurados de forma asociativa, como por ejemplo las instancias competentes». En particular, corresponde a los Länder la competencia de la parte escolar de la formación dual, así como de la mayoría de los programas de formación a tiempo completo en la escuela. Los agentes sociales participan, entre otros, en el desarrollo y modernización de los ordenamientos de la formación. Dado que no es posible obligar a las empresas a facilitar puestos de formación, «recae en los agentes sociales la responsabilidad de asegurar una suficiente oferta formativa». Sistema que recibe el nombre de modelo dual-corporativo, y que únicamente exist en determinadas zonas de influencia germanófilas en Europa (Alemania, Suiza, Austria y Dinamarca).

\section{Hacia una formación profesional comunitaria}

Los cambios técnicos y organizativos habidos durante la globalización, así como la revolución tecnológica de las últimas décadas del siglo $\mathrm{xx}$, hace necesario «contar con sistemas modernos y eficaces de formación profesional como instrumentos para la modernización económica, la participación con éxito en la economía global y la generación de mayor cohesión social» (CCOO, 2010: 31). Ello explica el porqué los «clásicos» modelos de FP hayan interaccionado entre ello, resistiendo el hecho de que las distinciones clásicas continúan manteniendo su esencia. De hecho, es lógico que esto haya ocurrido, ya que la FP constituye la «vía de adquisición de competencias y cualificaciones en un escenario de cambio constante», incrementando la formación de los trabajadores y adaptándose «a las necesidades del sistema productivo» (CCOO, 2010: 12). También la mejora de la empleabilidad favorece la inserción de los colectivos con más difícil acceso al mercado laboral, mujeres y jóvenes. Por otro lado, y bajo la influencia de las discusiones en varios Consejos Europeos, el término innovación se ha convertido en un factor clave para reforzar la relación entre la FP y la industria. Reforzar el poder innovador de la industria, de las empresas europeas y sus trabajadores, requiere de la innovación en los centros de FP. Ello necesita de una educación 
profesional basada en competencias en innovación, lo que exige modelos organizativos cooperativos centrados en: el estudiante, la cooperación entre la FP y el mundo empresarial.

Los modelos clásicos de FP comenzaron a mezclarse entre sí recientemente, y como consecuencia de los cambios técnicos y organizativos que han ocurrido durante la globalización neoliberal y la revolución tecnológica de las últimas décadas, si bien las distinciones clásicas continúan manteniendo su esencia. Una propuesta como esta es necesaria en el actual contexto, en el que se exige contar con sistemas modernos y eficaces de FP para la modernización económica, ya que aportan una mayor participación con éxito en la economía global, traduciéndose en la generación de más cohesión social. Esto explica el porqué el término innovación se ha convertido en un factor clave para reforzar la relación entre la FP y la industria, ya que fortalecer la potencialidad innovadora de la industria de las empresas europeas y de sus trabajadores requiere de la incorporación previa de la innovación en los centros de FP. No obstante, hemos de tener en cuenta que una educación profesional basada en competencias en innovación, exige modelos organizativos de FP centrados en el estudiante y en la cooperación entre éstos y el mundo empresarial. Cooperación orientada a fomentar la innovación tanto las instituciones educativas, como en empresas.

Los países que parecen haber aplicado mejor las estrategias de convergencia de la FP a escala europea, formuladas en el Comunicado de Maastricht de 2004, han sido los casos de Suecia, Noruega y Finlandia. Esto ha generado un interesante debate acerca de si la comparación entre modelos educativos constituye un instrumento para la construcción de un modelo formativo común dentro de la UE, el conocido como Espacio Europeo de Educación. Más concretamente, si este modelo compartido debe ser considerado una especie de factor común para los diferentes sistemas o si, en el fondo, se ha de tender tan sólo a copiar el modelo supuestamente más exitoso. El caso actual de la enseñanza superior, bajo el denominado proceso de Bolonia, parece priorizar la apuesta por copiar el modelo anglosajón (Merino, 2009a).

Una cuestión similar viene siendo la vivida en el ámbito de la FP. En éste siempre se ha utilizado al modelo dual alemán como referencia, debido a: su prestigio, al papel de las empresas en la formación (la llamada formación en alternancia) y a la regulación del mercado de trabajo que conecta con la FP. Este debate se originó a finales de la década de 1970, si bien se ha actualizado en nuestros días como consecuencia tanto de la globalización de la economía, como de las nuevas formas de utilización de mano de obra que están desafiando los distintos modelos de FP, ya que corren el riesgo de quedar se obsoletos, debido (como hemos tatado) 
a que surgieron bajo el paradigma de la construcción de estructuras políticas, industriales y profesionales de carácter nacional. Estrategias que, en opinión de Heikkinen (2004), respondieron a los desafíos por mejorar la competitividad, a través de la movilidad, la transferibilidad y la flexibilidad, y que solían asumir un «país» como punto de partida.

Los riesgos de la superación d eelas estructuras nacionales se encuentran entre los motivos por los que se buscan criterios comunes, junto a marcos y principios únicos para desarrollar la FP, así como la búsqueda de buenas prácticas de aplicación entre diversos países (Comisión Europea, 2005, 2007). Heikkinen (2004:34) así parece haberlo señalado, ya que en su opinión en las comparaciones internacionales, los modelos y prácticas de la FP se interpretan como un sistema único, lo que posibilita que «cuando se reconoce un alto grado de calidad y de buenas prácticas éstas suelen atribuirse al sistema de FP de un país concreto». Ello plantea una pregunta basada en por qué la difusión de buenas prácticas y la «adopción de marcos únicos» provocan diferencias entre países, motivo por el cual hemos de cuestionarnos acerca de «qué puede hacerse para mejorar sus sistemas», y ahí entra la omnicompresnión de sus estructuras socio-políticas. Es a partir de esta reflexión cuando debemos analizar los diferentes modelos clásicos en su conjunto, ya sea el modelo liberal o de mercado (Reino Unido, junto a Japón y los EEUU), ya sea el modelo burocrático o escolar (Francia, Italia, Escandinavia y España), o bien el modelo dual (Austria, Alemania, Dinamarca, Suiza).

\subsection{Iniciativas comunitarias de fomento de la FP, la Cedefop}

Todo lo expuesto nos permite comprender que el esfuerzo actual hacia la convergencia de los sistemas de FP, debe de ir acompañado de otras políticas estructurales y de intervención en los mercados de trabajo y en las administraciones públicas. Las últimas sentencias laborales europeas reconociendo igualad de derechos en mercados latamnte segmentados, apuntan hacia esa línea. De momento, pasamos a reseñar brevemente la historia de un encuentro.

El Tratado de Roma, en sus artículos 117 y 118, asignó las funciones generales a la FP, siendo: fomentar las oportunidades de empleo y la movilidad geográfica y profesional de los trabajadores; luchar contra el desempleo; facilitar el acceso al mundo del trabajo; y fomentar la igualdad de oportunidades en el mercado laboral, «desarrollando las competencias, aptitudes y cualificaciones profesionales y ayudar a la creación de nuevos puestos de trabajo» (n.d.* 4-5).

Para su organización fue creado, en 1975, el Centro Europeo para el Desarrollo de la Formación Profesional (Cedefop), con sede en Berlín Oeste. La caída del muro (1989, inicio de la reunificación alemana), como el Tratado de Maas- 
tricht (1992) tuvieron grandes consecuencias para el Cedefop. Acontecimientos que culminaron en el Consejo Europeo celebrado en Bruselas (1993), en el que se tomó la decisión de trasladar la sede del Centro hacia una zona geo-políticamente no central: «Alemania debía albergar al futuro Banco Central Europeo, mientras que Grecia no tenía hasta entonces ninguna entidad o institución europea dentro de su propio territorio» (Varsori, 2004:79). La búsqueda de cierto equilibrio institucional y político europeo hizo conveniente trasladar el Cedefop a Salónica (Varsori, 2004). Según Navarro (2014) este centro ha de respaldar la acción política europea en materia de FP y de aprendizaje permanente, por lo que está destinado a promover iniciativas dirigidas a facilitar un sistema común europeo de FP, con una salvedad. La asunción de que la política de FP guarda invariablemente relación con la estructura social, ya que las capacidades profesionales no dependen solamente de la docencia, sino también del conocimiento y del rendimiento económico, todas ellas instituciones sociales. Esta cooperación entre sistemas e instituciones se basa en la comprensión de que en un entorno económico transformado, el sistema de FP europeo en su conjunto debe adecuarse a éste para satisfacer las necesidades formativas de la economía, incorporando una mayor referencia al mercado y particularmente a los empresarios.

La propia Cedefop describe sus funciones: «uno de los mandatos del Cedefop consiste en informar acerca de los avances de los Estados miembros en la aplicación de las prioridades de la política europea de FP acordadas en el marco del proceso de Copenhague». Es por ello por lo que en 2012 examinó el progreso realizado en los objetivos intermedios por los 22 países miembros, en lo referente a lograr las metas estratégicas de la política europea de FP fijadas para 2020, fijados en el Comunicado de Brujas. En éste se puso de manifiesto que muchos países habían abordado algunos objetivos a corto plazo, «sobre todo los relacionados con los jóvenes», concretamente constató su esfuerzo «por reducir el abandono escolar prematuro». Junto al hecho destacable de que «en muchos países se constata una clara tendencia al desarrollo de programas de prácticas y otros tipos de aprendizaje basados en el trabajo», se evidenciónque «la FP no forma parte de muchas estrategias de innovación nacionales, y se precisa invertir más en la preparación de los profesores/formadores de FP»(Cedefop, 2013: 1).

Además del Cedefop, existen otras estructuras empeñadas en fomentar las oportunidades de empleo y la movilidad geográfica y profesional de los trabajadores son: el Comité Consultivo de la Formación Profesional, creado en 1963, e integrado por representantes de la Administración europea y representantes de las organizaciones empresariales y sindicales de los Estados miembros; y la Fundación Europea para la Formación Profesional, creada en 1994, centrada en la 
cooperación con los países de Europa Central y del Este y en la aplicación de los programas Tempus, Tacis y Phare. Todos estos centros e instituciones demuestran una evidente preocupación por el impulso de iniciativas dirigidas a atender a colectivos con mayores dificultades de inserción en el mercado de trabajo. Así, se constituyó la Iniciativa Comunitaria de Empleo y Desarrollo de los Recursos Humanos (1994-1999) que cuenta con tres capítulos: NOW, dirigido a mujeres; HORIZON/INTEGRA, destinado a colectivos desfavorecidos y personas con discapacidad; y YOUTHSTART, dirigido a jóvenes. También hay que mencionar la iniciativa ADAPT, centrada en promover la formación y cualificación de trabajadores afectados por cambios en el mercado de trabajo.

Desde comienzos del siglo xxi, continúan desarrollándose planes similares. El período 2000-2006 logró vincular las anteriores propuestas a la iniciativa EQUAL, proyecto bajo el que se agruparon todas las acciones dirigidas a luchar contra la desigualdad. Otras acciones son URBAN, dirigida a revitalizar económica y socialmente las ciudades y periferias en crisis, LEADER, centrada en el desarrollo rural e INTERREG III, dirigida a promover acciones transnacionales para fomentar el desarrollo armonioso, equilibrado y sostenible del conjunto del espacio comunitario. Las líneas y estrategias de esta actuación se concretaron ya a mediados de los ochenta en programas (que ahora se unifican) comunitarios: Lengua, centrado en el desarrollo de competencias lingüísticas; Comett I y Comett II, apoya la colaboración de empresas y universidades para el desarrollo de la FP en el campo de las nuevas tecnologías; Eurotecnet, fomenta la innovación en la FP; FORCE, fomenta la FP continúa; y PETRA, vinculada a la FP juvenil

Es posible que el Programa más vinculado al desarrollo de la FP sea el LEONARDO, dirigido precisamente a promover políticas comunes en esta etapa educativa. Su marco común recoge las grandes líneas inspiradoras de la política de FP Comunitaria: mejora de la calidad y capacidad de innovación de los sistemas, la promoción de la formación continua, el desarrollo y adquisición de competencias clave y lingüísticas, la adaptación de la formación a los cambios sociales y tecnológicos, el uso de las tecnologías de la información dentro de la formación abierta y a distancia, la formación para jóvenes y adultos sin formación y con riesgo de exclusión social y la transparencia de las cualificaciones.

En definitiva, según ha señalado Psifidou (2014:356), desde las últimas décadas del siglo xx exise una voluntad de desarrollar «una política común en materia de FP, esta política común no ha sido fácil de construir», debido a las reticencias de países que disponen de sistema de FP «bien desarrollados y no estaban muy dispuestos a asumir los costes que supondría la recualificación de la mano de obra de la Italia meridional», los casos de Alemania y Francia. No obstante, algo ha de 
cambiar, ya que como Pedraza (2002:2 ha señaldo, en la UE «se ha percibido un cambio de planteamiento entre los Tratados Constitutivos de la Comunidad Europea que establecen propuestas para elaborar una política común de Formación Profesional y los tratados posteriores, en concreto en el Tratado de Maastricht» el cual vino a conculcar la dualidad vivida has entonces, enla que a los Estados miembros les tocaba establecer sus respectivas políticas de FP, mientras que la tarea de la Unión Europea era la de facilitar y promover las líneas comunes de actuación «a través de instrumentos que faciliten el intercambio y la definición de políticas que promuevan este acercamiento, con el objeto de facilitar la movilidad de trabajadores y la transparencia de cualificaciones».

\section{Conclusiones}

A continuación presentamos un listado con las principales conclusiones extraídas del texto:

- La comprensión de los modelos nacionales de FP se han de vincular a aspectos que vayan más allá de vincular a la instrucción, también profesional en nuestro caso, a la integración en el mercado laboral. Para ello hemos apuntado la importancia del análisis discrónico, y de instituciones sociales como el mercado de trbajo y la adminutración central.

- La FP es una fomracón con una doble alma, profesionalizadora a la par que educativa, por lo este proyeto educativo genérico no pudo nacer al amparo de unas corporaciones profesionales medievales y modernas, que se dedicaron a transmitir los conocimientos necesarios para los respectivos oficios y su integrqación en la comunidad morlal sobre la que se articularon. Tan sólo podemos detectar rastros de transmisión de conocimiento del oficio.

- Por este motivo, los pirmeros esbozos de la FP, como formación integral, se han de buscar en las escuelas modernas de los estados absolutistas europeos, bajo claros intentos de homogeneizar a sus respectivos súbditos.

- Sin duda, nuestra actual FP, se hizo absolutamente imprescindble para el nuevo sistema fabril nacido bajo la industrialización, ya que ésta necesitó de la explotación racional y eficiente de una mano de obra de la que extraer la plusvalía productiva. Sin embargo, las culturas del trabajo nacieron con el capitalismo de base mercantill, vinculado a manufacturas y proto-fábricas, motivo por el que hay que prestarle mayr atención a sus estudios. 
- A partir de la II Revolución Indistrial, se molderaron los mercados de tabajo y se homogeneizaron la diferentes adimonistracioes centrales. No resulta extraño que, junto a los nuevos oficios industriales, como los maquinistas, naciesen los modelos «clásicos» de FP. Sobre ellos se han sentado las bases de los actuales modelos, surgen de un entorno mayor, por lo que hay que analizar sus contextos sociales y políticos.

- Históricamente el sistema de FP español, y con respecto a la FP reglada, se encuentra basado en el modelo burocrático y de regulación estatal (francés), por lo que no podemos vincularlo a un modelo en alternancia (como el germánico), de ahí los numerosos inconvenientes en la introducción de la FPdual, ni en el libre mercado británico.

- La actual convergencia de los citados modelos de FP ha sido impuesta pragmáticamente por el mercado, a la vez que ha sido planificada desde los orígenes de la propia UE, la cual vinculó desde su fundación (Tratado de Roma) la incorporación de la FP a la construcción europea.

- La velocidad de creación de un modelo único europeo de FP ha de salvar dos grandes escollos vinculados a intereses particulares de países concretos, como son Alemania y Francia. Por un lado, la negativa de éstos se basa en que ya disponen de modelos bien desarrollados y testados durante mucho tiempo; por otro, estos países plantean objeciones en lo referente al modelo único, ya que no están dispuestos a asumir los costes que supondría la recualificación de la mano de obra de los países mediterráneos en general.

- La visión de la FP ha cambiado en función de las exigencias del mercado, así ya no se trata de cualificar a trabajadores para el sistema productivo. También debe ser un instrumento para facilitar: la innovación, la creación de empleo asalariado, fomentar el autoempleo y el emprendimiento empresarial y promover el espíritu emprendedor. 


\section{Bibliografía}

Anderson, Fionnuala (2012). The Construction of Professionalism in Vocational Education and Training in Ireland: A mixed methods study of trainers' roles and professional development in the workplace. Dublin: Dublin City University.

Archer, Margaret (1979). Social origins of educational systems. London: Sage.

BAqués, Josep (2011). «El Estado», en Miquel Caminal (Ed.) (2011). Manual de Ciencia Política (pp. 42-66). 3 ed. Madrid: Tecnos.

Boli, John; Meyer, John; Ramírez, Francisco y Rubinson, Richard (1977). «The world educational revolution, 1950-1970», en Michael Hannah y John Meyer (Eds.) (1977). Sociology of education (pp. 242-258). Chicago: University of Chicago Press.

Boli, John y Ramirez, Francisco (1999), «La construcción política de la escolarización de masas: sus orígenes europeos e institucionalización de masas», en Mariano Fernández Enguita (Ed.) (1999). Sociología de la educación (pp. 297-314). Barcelona: Ariel.

Brunet Icart, Ignasi; Santamaria Velasco, Carlos Alberto; y Moral MarTín, J. David (2016). «Orígen de la Formación Profesional europea y actual tipología». En X Congreso de la red internacional de investigadores en competitividad. Ciudad de Puerto Vallarta, Jalisco, los días 9, 10 y 11 de noviembre de 2016.

CCOO (2010). «Informe conjunto sobre la formación profesional como factor de competitividad y de creación de empleo: prioridades de los agentes económicos y sociales». Disponible en: <http://www.navarra.ccoo.es/comunes/ recursos/1/doc29204_CESInforme_conjunto_sobre_la_formacion_profesional_como_factor_de_competitividad_y_de_creacion_de_empleo__ Prioridades_de_los_agentes_economicos_y_sociales.pdf $>$.

Cenefor (2008). Terminology of European education and training policy. A selection of 100 key terms. Luxembourg: Office for Official Publications of the European Communities.

- (2010a). La modernización de la formación profesional. Luxemburgo: Oficina de Publicaciones de la Unión Europea. Disponible a: <http://www.cedefop. europa.eu/en/Files/4068_ES.PDF >.

- (2010b). Vocational education and training: Key to the future. Luxembourg: Office for Official Publications of the European Communities.

- (2012). From Education to working life. The labour market outcomes of vocational education and training. Luxembourg: Office for Official Publications of the European Communities. 
Cedefop (2013). «Políticas de formación profesional y aprendizaje permanente más eficaces: concienciación, análisis y asesoramiento». Nota informativa. Disponible en: <https://www.sepe.es/contenidos/personas/formacion/refernet/pdf/breve-enero-2013_es.pdf $>$.

CES (2009). Sistema Educativo y Capital Humano. Madrid: CES.

CES (2011). La formación profesional como factor de competitividad y de creación de empleo: prioridades de los agentes económicos y sociales. Madrid: CES.

Collante de Terán Sánchez, Antonio (1992). «Solidaridades laborales en Castilla». En Cofradias, gremios, solidaridades en la Europa medieval. Actas de las XIX Semana de Estudios Medievales de Estella. 20-24 de julio de 1992, pp.113-126.

Comisión Europea (2005, 10 de noviembre). «Proposal for a recommendation of the European Parliament and of the Council on key competences for lifelong learning». COM (2005)548. Disponible en: <http://www .europarl.europa. eu/meetdocs/2004_2009/documents/com/com_com(2005)0548_/com_ com(2005)0548_en.pdf >.

- (2007). Towards a European qualifications framework for life-long learning. Consultation document. Bruselas: Directorate-General for Education and Culture.

De Pablo, Antonio (1997). «La nueva formación profesional: dificultades de una construcción». Revista Española de Investigaciones Sociológicas, 77-78: 137-162.

Euler, Dieter (2013). El sistema dual en Alemania. ¿Es posible transferir el modelo al extranjero?. Barcelona: Fundación Bertelsmann Stiftung.

Field, Simon; Kis, Viktória y Kuczera, Małgorzata (2012a). «Vocational education and training in Spain». En OECD, Postsecondary Vocational Education and Training Pathways and Partnerships. Paris: OECD Publishing.

- (2012b). «A skill beyond school commentary on Spain». OECD Reviews of Vocational Education and Training. Paris: OECD Publishing.

GaIrín, Joaquín (2009). «Formación profesional y ocupacional en el marco de la formación permanente. Una visión desde Europa». En Joaquín GaIrín, Miquel Àngel Essomba y Gelabert y Daniel Montané (Coords.) (2009). La calidad de la formación profesional en Europa, hoy: análisis de la situación y propuestas de mejora. Barcelona: Wolters Kluwer España.

Gallego, Elena (2009). Historia breve del Mercado de Trabajo. Ecobook, Madrid.

García López, Juan Ramón (2014). «El desempleo juvenil en España». ICE, 881: 11-28. 
Gracia Cárcamo, Juan (1991). «Un ejemplo del conflicto social en el artesanado de Bilbao: las fugas de aprendices (1600-1900)». Vasconia: Cuadernos de bistoria-geografía, 18: 109-121.

Greinert, Wolf-Dietrich (1999). Berufsqualifizierung und dritte Industrielle Revolution: eine historisch-vergleichende Studie zur Entwicklung der klassischen Ausbildungssysteme. Baden-Baden: Nomos Verlagsgesellschaft.

- (2004). «Los 'sistemas' europeos de formación profesional: algunas reflexiones sobre el contexto teórico de su evolución histórica». Revista europea de formación profesional, 32: 18-26.

- (2005). Mass vocational education and training in Europe: classical models of the 19th century and training in England, France and Germany during the first half of the 20th century. Luxemburgo: Oficina de Publicaciones Oficiales de las Comunidades europeas.

Heikninen, Anja (2004). «Modelos, paradigmas o culturas de la formación profesional». Revista Europea de Formación Profesional, 32: 34-48.

Kouknu, Aapo; Krrö, Matti; Packalén, Petra y Volmari, Kristiina (2012). Finland. VET in Europe - Country Report 2012. Refernet. Cedefop website: <http://libserver. cedefop.europa.eu/vetelib/2012/2012_CR_FI.pdf>.

LAski, Harold Joseph (2014). El liberalismo europeo. Fondo de Cultura Económica. México.

Martin Saint-León, Étienne (1947). Historia de las Corporaciones de Oficio. Partenón, Buenos Aires.

Mayntz, Renate (1985). Sociología de la Administración pública. Madrid: Alianza Editorial.

Merino, Rafael (2005a). «Apuntes de historia de la Formación Profesional reglada en España: algunas reflexiones para la situación actual». Tempora, 8: 211-236.

- (2005b). «Reforma i contrareforma de la formació profesional a la LGE i a la LOGSE. Alguna lliçó de la història recent per a la situació actual?». Educació i Història: Revista d'Història de l'Educació, 8: 263-282.

- (2009a). «El sistema de formación profesional en España: tendencias y debates». En Joaquín Gairín, Miquel Àngel Essomba y Gelabert y Daniel Montané (Coords.) (2009). La calidad de la formación profesional en Europa, hoy: análisis de la situación y propuestas de mejora. Barcelona: Wolters Kluwer España.

- (2009b). «Algunas reflexiones para la situación actual de la formación profesional reglada en España. Apuntes de historia». En Joaquín Gairín, Miquel Àngel Essomba y Gelabert y Daniel Montané (Coords.) (2009). 
La calidad de la formación profesional en Europa, hoy: análisis de la situación y propuestas de mejora. Barcelona: Wolters Kluwer España.

Merino, Rafael (2010). La formación profesional reglada en España: tendencias y debates. México: Editorial Praxis.

- (2013). «Las sucesivas reformas de la formación profesional en España o la paradoja entre integración y segregación escolar». Education Policy Analysis Archives/Archivos Analíticos de Politicas Educativas, 21: 1-15.

Michelsen, Svein y Høst, Håkon (2013). «Nasjonalt system og lokalt arbeid: Om kvalitet i fag- og yrkesopplæringen». En Håkon Høst (Ed.) (2013). Kvalitet ifag-og yrkesopplaringen. Fokus på skoleopplaringen. Rapport 2 Forskning på kvalitet i fag-og yrkesopplaringen. Oslo: NIFU.

Molas Ribalta (1970). Los gremios barceloneses. Confederación Española de Cajas de Ahorro, Madrid.

Molinas, César y García Perea, Pilar (2016). Poner fin al desempleo. ¿Queremos? ¿Podremos?. Bilbao: Deusto.

Moral Martín, J. David (2016). «Los orígenes del sindicalismo obrero: de las cofradías medievales a la clase laboriosa». Tesis inédita.

Moriel, Antonio (2012, 29 de mayo). La transición escuela trabajo en Alemania y España. Disponible en: <http://antoniomoriel.blogspot.com.es/2012/05/ la-transicion-escuela-trabajo-en.html $>$.

Navarro, Mikel (2014). «El papel de los centros de formación profesional en los sistemas de innovación regionales y locales. La experiencia del País Vasco». Cuadernos Orkestra 2014/7. Bilbao: Universidad de Deusto.

N.D. (n.d.). Capacitación laboral en la UE. Disponible en: <https*//studylib.es/ download/9073>.

Nilsson, Anders (2007). «¿Están las actuales estrategias nacionales de formación profesional en proceso de convergencia o de divergencia?». Revista Europea de Formación Profesional, 41: 168-181.

OCDE (2007a). OCDE Territorial Reviews Norway. París: OCDE.

OCDE (2007b). Learning for Jobs The OECD International Survey of VET Systems: First Results and Technical Report. París: OCDE.

OCDE (2015). Politica educativa en perspectiva 2015: hacer posible las reformas. Madrid: Fundación Santillana.

Ospino, Saulo (n.d.). Ciencia política. Disponible en: <http://derechoparaprincipiantes.jimdo.com/ciencia-pol\%C3\%ADtica/>.

Pedraza, Bonifacio (2000). «¿Hacia un modelo de cualificaciones profesionales en la Unión Europea? La propuesta de España y el Reino Unido». Revista Española de Educación Comparada, 6: 317-344. 
Pedraza, Bonifacio (2002). «La formación profesional en el entorno de la Unión Europea». OEI-Revista Iberoamericana de Educación, fecha de publicación: 26/06/2002.

Peugny, Camille (2009). Le déclassement. Paris‡ Grasset.

- (2013). Le destin au berceau. Inégalités et reproduction sociale. Paris: Seuil.

Pin, José Ramón; Roig, Marina; Susaeta, Lourdes y Apascaritei, Paula (2015). La formación profesional dual como reto nacional. Pamplona: IESE Business School-Universidad de Navarra.

Pirenne, Henri (2011). Las ciudades de la Edad Media. Madrid: Alianza.

Psifidou, I. (2014)+ «Evolución histórica de la formación profesional en Europa». Historia de la educación, 33: 353-359.

Puig i TARrech, Roser (1992). Els aprenents de Reus al final del s. XVIII (17731793). Reus: Ediciones del centre de lectura.

Recuperar Madrid (2009, 20 de noviembre). Sistema educativo y capital bumano. Disponible en: <http://recuperarmadrid.blogspot.com.es/2009/11/ sistema-educativo-y-capital-humano.html $>$.

Saunier, Georges (2004). «La formación profesional dentro de la idea de François Mitterrand de un espacio social europeo (1981-1984)». Revista Europea de Formación Profesional, 32: 83-89.

Sennet, Richard (2009). El artesano. Barcelona: Anagrama.

Tessaring, Manfred (1999). Formación para una sociedad en cambio: informe acerca de la situación actual de la investigación sobre la formacion profesional en Europa. 2 edición. Luxemburgo: Oficina de Publicaciones Oficiales de las Comunidades Europeas.

Tetrher, Bruce; Mina, Andrea; Consoli, Davide y Gagliardi, Dimitri (2005). A Literature Review on Skills and Innovation. How Does Successful Innovation Impact on the Demand of Skills and How Do Skills Drive Innovation? Manchester: ESRC Centre for Research on Innovation and Competition (CRIC), University of Manchester.

Toner, Phillip (2009). Workforce Skills and Innovation: An Overview of Major Themes in the Literature. Paris: OCDE.

Toner, Phillip (2010). «Innovation and Vocational Education». The Economic and Labour Relations Review, 21 (2): 75-98.

- (2011). "Workforce skills and innovation: an overview of major themes in the literature».STI working paper series SG/INNOV(2011)1. París: OCDE. Trinidad, A. (2008). «Sistema educativo y cualificación de recursos humanos». En Bericat, Eduardo y Echavarren, José Maria (comp.). Andalucía 2020: Escenarios previsibles. Sevilla: Fundación Centros de Estudios Andaluces. 
Unidad Permanente de Lisboa (2005). Convergencia y empleo. Programa Nacional de Reformas de España. Disponible en: <http://www.empleo.gob.es/ es/sec_trabajo/analisis-mercado-trabajo/pnr/archivos/PNR_axos_anteriores/Programa_Nacional_de_Reformas_2005.pdf $>$.

Uña de Sarthou, Juán (1900). Las Asociaciones obreras en España: notas para su historia. Establecimiento Tipográfico de G. Juste, Madrid.

VArsori, Antonio (2004). «El papel de la formación profesional en la política social europea y el Cedefop». Revista Europea de Formación Profesional, 32: 68-82.

Viñao, Antonio (1982). Política y educación en los origenes de la España contemporánea. Madrid: Siglo XXI.

Virtanen, Anne; Trnjälä, Päivi y Stenström, Marja-Leena (2008). «Fieldspecific educational practices as a source for students' vocational identity formation». En Billett, Stephen; Harteis, Christian y Eteläpelto, Anneli (Eds.). Emerging Perspectives of Workplace Learning (pp. 19-34). Rotterdam: Sense.

Wallerstein, Immanuel (1979). El moderno sistema mundial, La agricultura capitalista y los orígenes de la economía-mundo europea en el siglo XVI. Madrid: Siglo XXI.

Weber, Max (1987). La ciudad. Madrid: La Piqueta.

- (2002). Economia y sociedad. Madrid: Siglo XXI.

Wollschläger, Norbert, y Reuter-Kumpmann, Helga (2004). «De la divergencia a la convergencia: Una historia de la formación profesional en Europa». Revista Europea de Formación Profesional, 32: 6-17. 